\section{Can I assist with sedation?}

I hope you can advise me on the following.

I am a registered dental nurse and have been working in practice for the past ten years.

I have been assisting with sedation patients but am now unsure how I stand with registration now in place. My dentist occasionally carries out sedation treatment now but not on a regular basis and I am wondering if I need to have a post qualification in sedation to be able to assist with these patients.

Would you be able to give me any information please?

\section{Carly Johnson \\ By email}

Elizabeth Curtis at the GDC responds: General Dental Council standards guidance is a code of behaviour that you agree to abide by as a registered DCP. This is one of the main ways in which we protect patients, but standards also protect DCPs by making it clear what is expected of you.

Our guidance is not made of lists of rules about what registrants should and shouldn't do. Instead the guidance sets out the principles and values that DCPs should work with when making decisions. It is their responsibility to apply these principles to their daily work, using their judgement in the light of the principles. $D C P$ s have a professional responsibility to be prepared to justify their actions, and we may ask registrants to do so.

Our Scope of practice guidance states: Additional skills dental nurses could develop during their careers include:

- Assisting in the treatment of patients who are under conscious sedation.

Additional skills are those a DCP may wish to develop after they have registered. There are different ways of doing this - the key point is to only carry out a task or type of treatment, or make decisions about a patient's care if you are sure you have the necessary skills.

Further information about conscious sedation can be found on page 10 of this document - our Standards for dental professionals.

http://www.gdc-uk.org/NR/rdonlyres/1B66D814 A197-4253-B331-A2DB7F3254DC/0

StandardsforDentalProfessionals.pdf

You may also wish to consult your indemnity provider to see if they have a view on this particular issue.

\title{
Effective safety equipment
}

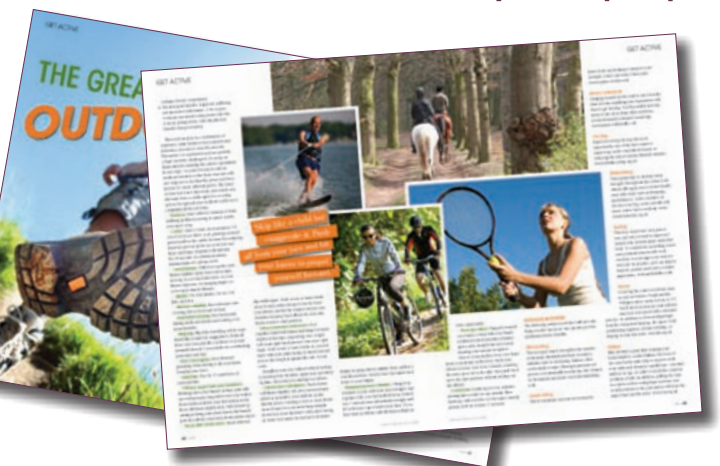

sustained by up to $46 \%$ of children having cycle accidents. ${ }^{1}$ A Cochrane Review by Thompson, Rivara and Thompson in $2000^{2}$ concluded that 'Helmets reduce bicycle-related head and facial injuries for bicyclists of all ages involved in all types of crashes including those involving motor vehicles.'

Surely, we should at the very minimum, represent the use of effective safety equipment, even if we then choose to ignore the evidence ourselves?

I have just browsed my autumn copy of Vital. I am somewhat disappointed by the choice of the illustration of mountain biking (page 48) - the rider in the foreground is wearing her helmet on the handlebars of her bike. This hardly fits with the dental profession's role in health promotion.

One can unexpectedly strike a stone or tree root and go over the handlebars or face-butt them when one is least expecting it. Indeed, there are 100,000 off-road cycling accidents per year, of which $47 \%$ involve adults. In children, a third of deaths and the majority of injuries occur off-road. There were, in the UK, between 127 and 203 cycling fatalities per year between 1996 and 2002, of which 70-80\% were caused by traumatic brain injury. Facial injuries are

\section{Helen R. Chapman \\ Horsham}

1. Chapman H R, Curran A L M. Bicycle helmets - does the dental profession have a role in promotion? Br Dent J 2005; 196: 555 560.

2. Thompson D C, Rivara F P, Thompson R. Helmets for preventing head and facial injuries in bicyclists. Cochrane Database Syst Rev 2000; CD001855.

Ed's note: We are very sorry for the poor choice of stock photograph used in this article and would like to thank Helen for drawing our attention to it.

\section{Q. What do you like best about your job in dentistry?}

\section{A. Making a difference}

Sadly there are still many people who fear going to the dentist. If we can play a small part in helping to reduce their concerns and encourage them to attend without worry, by smiling, answering their questions and helping them to realise that modern dentistry is pain free. We can make a big difference to their life and general health and help prevent the most common dental diseases.

\section{Kirsty Stevens} Lecturer, West Kent College

\section{A. My lovely boss}

\section{Sarah Edwards \\ Dental Nurse, Slough}

\section{A. Supporting my patients and seeing results}

The best thing about my job in dentistry is the reward of patients seeing the results of their own hard work with oral hygiene. It is also so rewarding to support my patients through the ups and downs of their lives.

\section{Mhari Coxon \\ Dental Hygienist and Director, CPDforDCP Ltd}

